\title{
Research into the Relationship of the Development between the Sports Industry Cluster and the Regional Economy \\ Zhaoyuan Huang
}

Institute of Physical Education, Changchun Normal University, Changchun Jilin Province ,China

hzy1353160@sina.com

Keywords:Industry Cluster; Sports Industry Cluster; Economy; Development

\begin{abstract}
In this paper, the literature method is used to discuss the relationship between the formation of the sports industry cluster and the growth of the regional economy. According to the research, there are some problems existing in the development of the regional sports industry cluster of China, and relationship needs further defining, and some improvement suggestions and measures are to be implemented in order to have complementary advantages and to promote the sound development of regional economy.
\end{abstract}

\section{Introduction}

Since the reform and the opening-up, the State Council has decided to implement "Six-izations and six transformations" wherein the socialization and industrialization-oriented strategic reform drives the development of the sports industry to start slowly; the operation activities in the sports field become increasingly active, and sports, bodybuilding, entertainment, the competition show markets have become the core element markets for the development of the sports industry. The status of the sports industry has established[1]. Through the leapfrog development over the past thirty years, the sports industry plays an irreplaceable part in improving the structure of the regional economy, enriching the cultural life of the communities, improving the city's functions and reputations as well as enhancing the citizens' physique and health and others. In addition, there will be no drive to the development of the industry without large scale or further synergy effects with other industries.

\section{Definition of the Concept of Sports Industry Cluster}

The sports industry is a sports industry cluster having the characteristics of gathering in specific zones, specialized production of products, division of the work between enterprises, integrity of industry chain. The sports industry cluster appears in order to meet the internal requirements for the development of the society and highlight the intermediate links of the diversified and specialized sports industry chain[2].

In this study, the sports industry cluster is defined as the combination of life functions of organisms that play a part in the enterprises and support systems which are interlinked and exert influence on each other in some regions around the sports industry chain. The support system herein mainly refers to scientific institutions, governmental authorities, and resource endowments. In the sports service industry, the enterprises that are interlinked with and exert influence on each other may be not only sporting goods industry, sports enterprises, but also other related enterprises, including the upstream enterprises producing raw materials, and upstream and downstream enterprises to meet the demands of consumers.

\section{Analysis of the Necessity for the Formation and Development of the Sports Industry Cluster}

Seen from the angle of resource endowment, the sports industry cluster is a mode for allocating the resources for the economic activities that are most advantageous to a region by effectively organizing the elements of the sports industry in the region in an effective way. Seen from the angle of the economic system, the sports industry cluster is integrated with the theories and mechanisms of the 
sports industry and the industry cluster for multi-layer and multi-structure regional system of sports economic activities and strategic alliance among sports enterprises, and has outstanding industry cluster advantages and the effects of driving radiation[3]. The sports industry cluster is helpful for reducing the operation cost of enterprises in the clusters, promoting the continuous innovation of enterprises in the cluster, making the capital of the sports industry in the cluster more attractive and driving the reform and development of the enterprises in the cluster. With the creation and development of the sports industry cluster, wider, bigger and more powerful sports industry cluster zones with definite work division between upstream and downstream enterprises and with closer relationships between the enterprises are formed so as to promote the development of the regional sports industries better.

\section{Relationship between the Development of the Sports Industry and the Growth of the Regional Economy}

In recent dozens of years, as more and more people participate in sports, all of the economic activities associated with the sports are fully developed, and the sports industry has become an independent industry playing an important part in promoting the growth of regional economies. Sports, as an important constituent in social culture, belongs to social welfare contrasting to material production, and its development to depends on the level of development of regional economies (consumers' concepts and the investment on the sports in regions and the country) to a great extent. Analyzed from the relationship between sports and economy, economy is the basis of sports, and the development of sports depends on the development of the economy; and the level of regional economy decides the level of the regional sports development fundamentally. According to related researches, the development of the sports industry cluster is closely associated with the level of the development of the regional economy and the per capita income, and the development of regional economy directly decides the investment of the society on the sports industry; the per capita income directly decides the demands for consumption of sports of the people[4]. The increase of the demand for sports and the consumption of sports arising from the development of the regional economy and the increase of the citizens' income is the basis for the existence and the development of the regional sports industry cluster.

As Chinese economy keeps growing and the material and cultural life keeps improving, the demand for consumptions of sports gradually grows. Various bodybuilding sports, leisure sports thrive all over the country, and the development of the sports industry not only provides a lot of sports service goods, sports information goods and other derivative goods for the people, and large-scale sports market gradually forms, namely, the sports industry cluster, which plays a big part in promoting the development of the regional economy[5]. Besides, under the conditions of market economy, vigorous development of the sports may help to increase the job vacancies, relieve the serious employment problems during the development of Chinese society. According to the data of the Twelfth Five-Year Plan in the Development of Sports, great progress has achieved during the Eleventh Five Year in the Development of the Sports Industry of China. Taking 2012 for example, up to 3.7562 million persons work in the sports industry throughout China, and the increment of value in the industry is up to 313.595 billion Yuan and the value of the sports industry accounts for $0.6 \%$ of GDP[6]. In particular in recent two years, as Chinese economy keeps developing, people's demand for sports grows increasingly. The domestic sports market has gained continuous development and progress, and has become a new force in the development of the national economy.

\section{Problems in the Development of Chinese Regional Sports Industry Cluster}

\footnotetext{
Shortage of Professionals in the Sports Industry, and Insufficient Utilization and Exploration of Regional Sports Resources. At present, great attention shall be attached to exploration and
} 
utilization of the regional sports resources and development of professionals in the industry[7]. Low level of professionalism of the persons in the sports industry is a very outstanding realistic problem. Due to non-understanding of the sports industry, narrow research field of the sports industry, and low correlation degree of research, the division of work in the sports industry is not so diversified, and the professionalism level is low; persons engaged in the industry don't correlate the sports industry with other industries often, and are not good at creating derivatives.

Government does not Tend to Play a Part in Building the Sports Industry Cluster.The continuous stable development of the regions is based on the premise of effective allocation of relevant elements in both timing and space[8]. The efficiency of allocating various elements in timing and space during the gathering of the regional sports industry not only decides the overall benefits of the regions arising from the clustering, but also decides the potential and the appropriateness of the regional development. Due to the instinct defects in the sports market mechanism and the space property of the regional economy, it is difficult to ensure that the regional economy to develop in the optimum path all along simply by virtue of the force of the sports market. In particular as the economic mechanism of the market of China is not well developed, the government plays an important part in the growth of the sports industry cluster.

The sports industry does not belong to the first industry or the second industry, and is an important constituent in the service industry, and requires a high level of consumption of the social citizens[9]. Under such a circumstance, the reliance of the formation of the sports industry cluster on the government is obvious, and it is difficult to guarantee the formation of the sports industry cluster when the government fails to play a part in it.

Few Specialized Industry Organizations or Broker Organizations.Since the predominant role of the sports industry was established, it is obvious to us that in the sports, bodybuilding and entertainment industry, the competition is disordered with price wars and cheating wars occurring again and again, and it is impossible for us to effectively guarantee the clients' benefits. This situation becomes a great threat to the formation of a regional sports industry cluster to some extent.

\section{Measures and Suggestions for the Development of the Regional Sports Industry Cluster of China}

Speeding up the Development of Professionals to Provide Human Resources for Improving the Development of the Sports Industry Cluster.At present, most of sports persons are developed in sports universities and schools, in addition, the persons developed in sports universities and schools are not developed in consideration of the current development of the industry. Accordingly, resources are wasted, and the students fail to meet the requirements of social development. Accordingly, it is suggested that the cooperation with the faculties of the industrial economy of comprehensive universities and schools shall be reinforced and students shall be helped to be integrated into the industrial development quickly by building some practical training grounds[10].

Improving the Local government's Functions in the Formation and Development of the Regional Sports Industry Cluster.In the main industry of sports, the market has partially failed during actual operation. Monopoly in sports competitions, and vicious competition in the sports, building and entertainment industry are the proof of this issue and government shall give assistance and support to this. 
Reinforcing the Linkage between the Sports Industry and other Industries, and Improving the Industrial Chain.The formation of the sports industry cluster is just one part of the industrial division of work and specialized development, and proper integration of other industries into the sports industry and proper division of work among the industries play an important part in driving the expansion of the industrial chain of the sports industry cluster, improving the specialism and improving the varieties of the products. By building the sports industry cluster, a very proper platform is provided for bonding and graft of the sports industry to promote the development of the sports industry cluster.

\section{References}

[1] Information on https://en.wikipedia.org/wiki/North_East_of_England_Process_Industry_Cluster

[2] Yang Ming, Development of the Sports Goods Industry Cluster of China and Research into the Government's Policies.Sports and Science,5(2007)11-19

[3] Wang Jian, Han Jianlei. Research into the Development Strategies of Jiangxi Sports Industry Cluster. Social Sciences of Jiangxi, 5(2012)65-70

[4] Song Yingjie. Discussion of the Sports Industry Cluster and the Regional Economic Development.Journal of Langfang Teachers University(Natural Science Version),1(2011)8-15

[5] Liu Bing, Rui Mingjie. Development of the Sports Industry Cluster based on the Specialized Work Division. Journal of Shanghai University of Sport, 3(2009)37-42

[6] Liu Bing, Dong Chunhua. Research into the Formation of the Sports Industry Cluster and the Regional Development Relationship.Sports Science,2(2010)153-157

[7] Zhang Guihai, Li Songmei. About the Regional Cooperation of the Skiing Sport Tourism of the Northeastern Area of China.Ice and Snow Sport. 2014(03):109-111

[8] Zhang Yi, Pang Guoqing. Research into the Development of the Leisure Sport Industry of the Northern Bank of Taihu Lake.Journal of Huzhou Normal University. 2012(01): 83-86

[9] Information on http://libra.msra.cn/Publication/51115561/the-research-of-identification-and-determination-forsports-industry-cluster

[10]Minghu, Li Jianshe, Empirical Research into the Regional Manufacturing Industry Cluster of Sports Goods-Taking Zhejiang for Example.Sports Science of Zhejiang,8 (2007)117-121 